\title{
Quality of life among patients with cardiac disease: the impact of comorbid depression
}

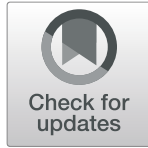

Mandreker Bahall ${ }^{*} \mathbb{D}$, George Legall and Katija Khan

\begin{abstract}
Background: Patients with cardiac disease with or without depression may also have major physical and mental problems. This study assesses and compares the quality of life (QOL) of patients with cardiac disease with and without depression and accompanying comorbidities.

Methods: A cross-sectional study was conducted with a convenience sample of 388 patients with cardiac disease. The 12-item Short-Form (SF-12)-patient was used to measure physical component scale (PCS) and mental component scale (MCS) QOL, and the Patient Health Questionnaire (PHQ-9) was used to measure depression. The Charlson Comorbidity Index was used to estimate 10-year survival probability. Descriptive statistics, analysis of covariance (ANCOVA), chi-square tests, and binary logistic regression were used for analysis.

Results: The prevalence of minimal to mild depression was $65.7 \%$ [ $(95 \% \mathrm{Cl}(60.8,70.4)]$ and that of moderate to severe depression was 34.3\% [95\% Cl $(29.6,39.2)]$. There was no significant association between the level of PHQcategorised depression and age $(p=0.171)$, sex $(p=0.079)$, or ethnicity $(p=0.407)$. The overall mean PCS and MCS QOL was 32.5 [95\% Cl $(24.4,40.64)]$ and $45.4[95 \% \mathrm{Cl}(44.4,46.4)]$, respectively, with no significant correlation between PCS and MCS [r (Pearson's) $=0.011 ; p=0.830)]$. There were QOL differences among the five PHQ categories (PCS: $p=$ 0.028 ; MCS: $p \leq 0.001$ ) with both MCS and PCS decreasing with increasing depression. ANCOVA (with number of comorbidities as the covariate) showed a significant age $\times$ ethnicity interaction for PCS ( $p=0.044)$ and MCS ( $p=0.039)$, respectively. Young Indo-Trinidadians had significantly lower PCS than did Afro-Trinidadians, while the converse was true for MCS. Depression, age, and number of comorbidities were predictors of PCS, while depression, age, and sex were predictors of MCS.
\end{abstract}

Conclusions: Increasing severity of depression worsened both PCS and MCS QOL. Age and level of clinical depression predicted QOL, with number of comorbidities predicting only PCS and sex predicting only MCS. Efforts must be made to treat depression in all age groups of patients with cardiac disease.

Keywords: Depression, Quality of life, Cardiac comorbidities, PHQ-9, SF12, PCS, MCS

\section{Background}

Quality of life (QOL) is a major outcome indicator of patients with cardiac disease with or without comorbidities such as depression, other psychosocial factors, and a multitude of chronic non-communicable diseases. Depression, defined by the World Health Organization (WHO)

\section{* Correspondence: vmandrakes@hotmail.com}

School of Medicine, Faculty of Medical Sciences, University of the West Indies, Eric Williams Medical Sciences Complex, Mt Hope, House \#57 LP 62, Calcutta Road Number 3, Mc Bean, Couva, Trinidad, Trinidad and Tobago as "a common mental disorder, characterised by sadness, loss of interest or pleasure, feelings of guilt or low selfworth, disturbed sleep or appetite, feelings of tiredness, and poor concentration" [1], is quite prevalent worldwide. It can be "long lasting or recurrent, substantially impairing a person's ability to function at work or school, or cope with daily life" [1]. Depression remains one of the most prevalent diseases globally, with the 12-month and lifetime prevalence of major depressive disorder being 10.4 and 20.6\%, respectively, in the US [2]. In Trinidad and Tobago,

(c) The Author(s). 2020 Open Access This article is licensed under a Creative Commons Attribution 4.0 International License, which permits use, sharing, adaptation, distribution and reproduction in any medium or format, as long as you give appropriate credit to the original author(s) and the source, provide a link to the Creative Commons licence, and indicate if changes were made. The images or other third party material in this article are included in the article's Creative Commons licence, unless indicated otherwise in a credit line to the material. If material is not included in the article's Creative Commons licence and your intended use is not permitted by statutory regulation or exceeds the permitted use, you will need to obtain permission directly from the copyright holder. To view a copy of this licence, visit http://creativecommons.org/licenses/by/4.0/. The Creative Commons Public Domain Dedication waiver (http://creativecommons.org/publicdomain/zero/1.0/) applies to the data made available in this article, unless otherwise stated in a credit line to the data. 
depression accounted for 30\% of the reported cases of mental illnesses [3]. Among patients with cardiac disease, depression ranges between 20 and 40\% [4]. In Trinidad, $40 \%$ of stable (i.e. without deterioration, and able to perform basic activities of daily living) patients with cardiac disease were found to have depression [5].

Depression is associated with worsened QOL (physical, mental, and social), [6-8] medical morbidity, and mortality [9]. A strong association has been observed between symptoms of depression and health status, symptom burden, physical limitation, QOL, and overall health among patients with coronary artery disease (CAD) [10]. Depression influences lifestyle habits such as smoking, eating, exercising, getting along with family members, social life, and work $[4,11]$. It can lead to lowered productivity, personal losses, and increased family and state burden. Other accompanying cardiovascular risks can further compromise patient QOL [12-15]. Many studies in developing countries have reported on poor QOL experienced by patients with cardiac disease with depression [16] who are two times more likely to die after a cardiac event [17]. Studies on QOL among patients with cardiac disease with depression have not been reported in Trinidad and Tobago. This study sought to examine and compare QOL among, and between, patients with cardiac disease with or without depression admitted to public tertiary health institutions in Trinidad and Tobago.

\section{Methods}

This was a cross-sectional study, the target population being all patients presenting with cardiac disease at the three teaching hospitals in Trinidad and Tobago during the period November 2015 to March 2016. The population from which the sample was taken comprised all patients attending the cardiac clinic from the largest teaching hospital because by the time of study initiation, approval had been granted only by the largest hospital where the study was conducted. The hospital is a 745bed facility that offers free public healthcare to a catchment of 600,000 persons. Annually, there are 46,785 admissions to this hospital, of which 15,339 (32.8\%) are medical admissions (2010) [18]. Because of the protocols used for patient admission in these three hospitals, there is no reason to expect that the patients treated for CVD at this institution significantly differed from those treated in the non-participating hospitals during the study period in any characteristic (age, sex, and ethnicity) that would affect the findings of the study due to non-participation.

To be eligible for participation in the study, patients were to have been diagnosed with cardiac disease at least 3 months prior to the start of the study. The patients' medical records in the cardiac clinic were used to create a sampling frame from which patients were selected.
Inclusion criteria were 18 years of age or older and willingness to communicate for approximately $20 \mathrm{~min}$. Exclusion criteria were confusion (incoherence), refusal to participate, poor health status (signs of mental and physical exhaustion), and unavailability at the time of selection. A sample size of 396 patients was computed to be the minimum needed in order to estimate the prevalence of depression within the target population with a $5 \%$ margin of error using simple random (probability) sampling [19].

Two data collection instruments, namely, the 12-item Short-Form 12 patient questionnaire to measure QOL and the Patient Health Questionnaire (PHQ-9), were used to measure depression. In addition, selected demographic variables such as age, sex, ethnicity, and education were included in the questionnaire. In keeping with standard depression research guidelines, patients with PHQ-9 scores $\geq 10$ (out of 27) were classified as having clinically significant depression [20]. SF-12 data were used to measure both Physical QOL, i.e. the physical component score (PCS) and Mental QOL, i.e. the mental component score (MCS). Lower mean scores indicate poorer QOL. The Charlson Comorbidity Index [21] was used to classify patients according to their estimated 10-year survival probability (See Fig. 1). The Charlson Comorbidity Index, which is the probability of 10 year survival, was preferred to the number of comorbidities, which provides a measure of the prevalence of the number of comorbidities. It is also a more appropriate covariate when comparing QOL means using analysis of covariance (ANCOVA).

The SF12 comprises 12 questions on the general rating of one's health, limitations imposed by current health status on moderate activities and climbing several flights of stairs, experiencing problems with work or regular daily activities due to physical health and emotional problems, how pain interferes with one's normal work, assessing patient emotional state during the past 4 weeks and how much of the time has physical health or emotional health interfered with social activities. The SF12 yields two summary measures, namely, a Physical Component (PCS QOL) and a Mental component (MCS QOL), which were generated using standardised scoring guidelines [22, 23].

SPSS, version 21 (IBM Corp., Armonk, NY), was used for data analysis, by means of both descriptive and inferential methods. Descriptive methods included determining frequency and percentage distributions and summary statistics (means and standard deviations). Inferential methods included 95\% confidence intervals (CI), hypothesis testing, and prediction (regression analysis). ANCOVA was used to test the equality of mean PCS and mean MCS QOL scores, using the Charlson Comorbidity Index as a covariate. McNemar's test of paired proportions was used to test the 


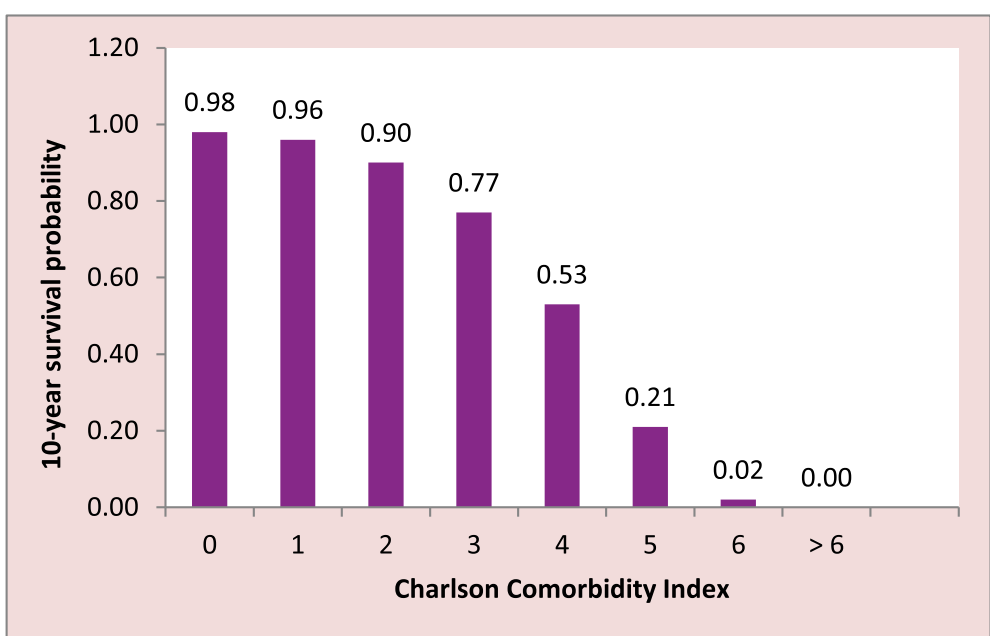

Fig. 1 Charlson Comorbidity Index and the corresponding 10-year survival probability

association between self-reported depression and SF12diagnosed depression. Microsoft EXCEL was used to produce tables, graphs, and charts.

\section{Results}

\section{Demographics}

By the end of the data collection period, 388 (98.0\%) of the 396 patients were surveyed. Patients were predominantly female $(n=207,53.4 \%)$, aged $65-74$ years $(n=121$, $31.2 \%)$, and Indo-Trinidadian ( $n=280 ; 72.2 \%$; Table 1$)$.

The overall mean age was $64.1 \pm 13.37$ years; male participant age was $62.4 \pm 14.10$ years, and female participant age was $65.6 \pm 12.55$ years, with women being significantly older than men $(p=0.019)$. The difference

Table 1 Frequency and percent distribution of demographic variables

\begin{tabular}{lll}
\hline Variable & $\mathrm{n}$ & $\%$ \\
\hline Sex & 181 & \\
Male & 207 & 56.6 \\
$\quad$ Female & & \\
Age group (years) & 11 & 2.8 \\
$<35$ & 24 & 6.2 \\
$35-44$ & 50 & 12.9 \\
$45-54$ & 97 & 25.0 \\
$55-64$ & 121 & 31.2 \\
$65-74$ & 85 & 21.9 \\
$\geq 75$ & & \\
Ethnicity & 83 & 21.4 \\
Afro-Trinidadian & 280 & 72.2 \\
Indo-Trinidadian & 25 & 6.4 \\
Other & & \\
\hline
\end{tabular}

between the mean age of Afro-Trinidadian and IndoTrinidadian patients was not significant $(p=0.877)$. Hypertension was the most prevalent comorbidity at $84.5 \%$ [95\% CI $(80.5,88.0)]$, followed by diabetes at $65.7 \%$ [95\% CI $(60.8,70.4)]$ and hypercholesterolaemia at $21.9 \%$ [95\% CI $(17.9,26.4)]$. Cancer was the least prevalent comorbidity at $2.8 \%$ [95\% CI $(1.4,5.0)]$, and selfclaimed stressful life was reported by $53.9 \%$ [95\% CI (48.8, 58.9); Fig. 2]. In addition, $52.6 \%$ of participants had a family history of ischemic heart disease (IHD), $19.3 \%$ had a history of stroke or transient ischaemic attack, and $5.6 \%$ had peripheral vascular disease. Cardiac investigations performed included angiography (31.7\%), coronary artery bypass grafting (7.7\%), and angioplasty (7.5\%).

The number of comorbidities ranged from $0(n=37$, $9.5 \%)$ to $4(n=2,0.5 \%)$ [mean: $1.6 \pm 0.782$, median: 2 , mode: $2(n=207,53.4 \%)]$. Figure 3 shows the percentage distribution of the Charlson Comorbidity Index. As seen, 4-year CVD ( $n=96 ; 24.7 \%)$, corresponding to a 10 -year CVD survival probability of $53 \%$, was the index with the highest prevalence. Figures 1 and 3 together show that $5.9 \%$ [95\% CI $(3.8,8.8)]$ of the patients had a $98.0 \% 10$ year survival probability (Charlson Comorbidity Index = $0)$ and $6.1 \%[95 \%$ CI $(2.6,6.9)]$ had a zero 10 -year survival probability.

Only $7.5 \%$ [95\% CI $(5.1,10.6)]$ of the patients lived alone; $13.1 \%$ [95\% CI $(9.9,16.9)]$ lived with a spouse only, while $20.2 \%$ [95\% CI $(16.2,24.4)]$ lived with a relative, and $49.2 \%$ [95\% CI $(44.1,54.3)]$ lived with a spouse and at least one relative.

\section{Physical and mental quality of life}

The PCS and MCS from the SF12, demographics, and Charlson Comorbidity Index are shown in Table 2. The 


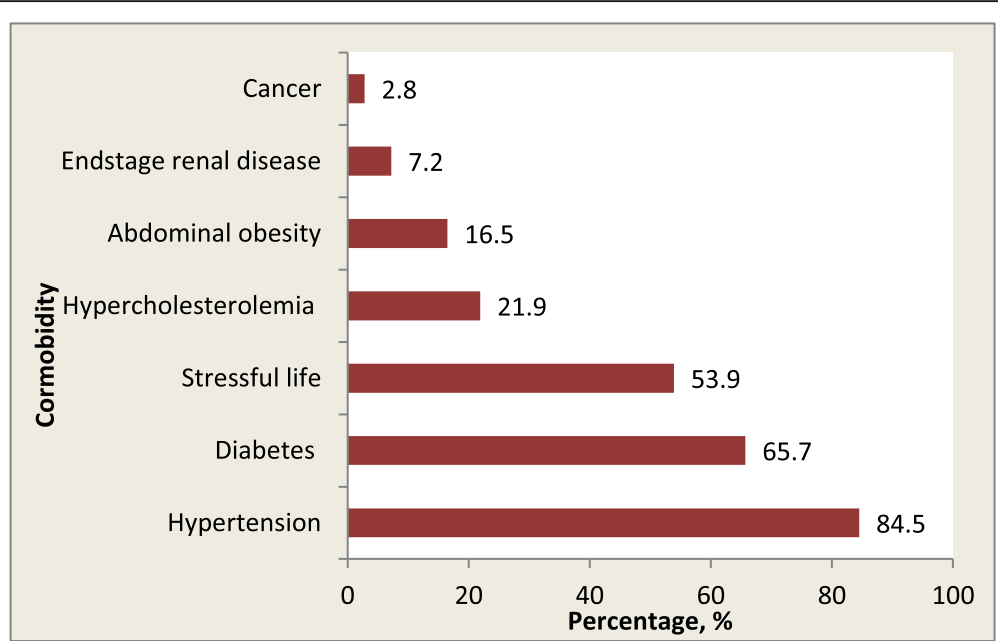

Fig. 2 Prevalence of comorbidities among patients with cardiac disease

overall mean PCS and MCS QOL were 32.5 [95\% CI $(24.4,40.64)]$ and 45.4 [95\% CI $(44.4,46.4)]$, respectively. The scatterplot of PCS vs. MCS with the linear regression line (Fig. 4) showed no discernible linear or nonlinear pattern or trend. Bivariate correlation analysis showed a Pearson coefficient $(\mathrm{r})$ of $0.011(p=0.7830)$ for MCS and PCS.

\section{Depression: self-reported and PHQ diagnosed}

The overall prevalence of PHQ-categorised depression was $78.4 \%$ [(95\% CI $(73.9,82.3)]$ ranging from mild [38.4\%; 95\% CI $(33.5,43.4)]$ to severe [2.3\%; $95 \%$ CI $(1.1$, 4.4)]. At the same time, the prevalence of clinical depression ( $\mathrm{PHQ} \geq 10)$ was $34.3 \%$ [95\% CI $(29.6,39.2)]$ compared to a $38.4 \%$ [95\% CI $(33.5,43.8)]$ prevalence of selfreported depression (Table 3). The difference was not significant (McNemar's test of equality of paired proportions; $p=0.171$ ). Additionally, chi-square analysis showed no association between clinical depression level and age $(p=0.171)$, sex $(p=0.079)$, or ethnicity $(p=$ 0.407).

\section{Depression/comorbidities and quality of life}

ANCOVA with number of comorbidities as the only covariate showed significant differences in the mean MCS between patients in the five PHQ depression categories $(p=0.029)$ and a significant Age $\times$ Ethnicity interaction $(p=0.045)$. The adjusted means and corresponding standard deviations, along with the number of patients, are shown in the second column of Table 4. As shown, patients with no depression had higher mean PCS than those in every depression category and the mean MCS decreased with increasing levels of depression. This would be later confirmed by regression analysis.

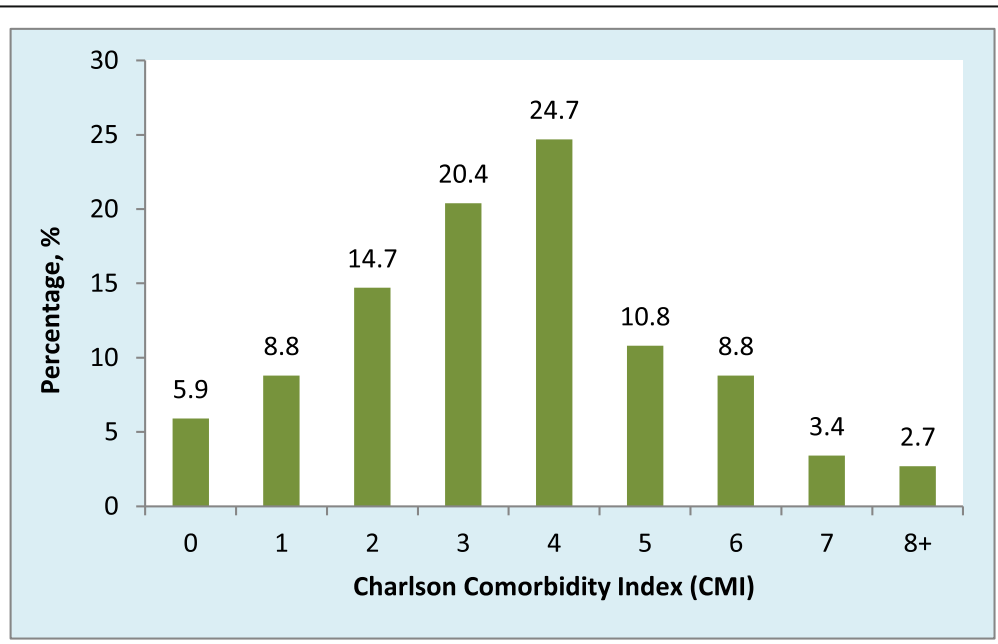

Fig. 3 Charlson Comorbidity Index distribution of patients 
Table 2 SF-12 domain scores by patient characteristics

\begin{tabular}{lll}
\hline Variable & QOL: Mean (SD) & \\
\cline { 2 - 3 } & PCS & MCS \\
\hline Sex & $32.7(8.60)$ & $47.6(10.07)$ \\
Male & $30.6(7.64)$ & $43.5(10.13)$ \\
Female & & \\
Age group (years) & $37.2(9.86)$ & $43.5(15.01)$ \\
$<35$ & $35.2(8.53)$ & $44.6(11.43)$ \\
$35-44$ & $34.0(7.36)$ & $44.8(9.84)$ \\
$45-54$ & $32.0(8.84)$ & $45.4(10.74)$ \\
$55-64$ & $29.9(7.72)$ & $45.7(9.61)$ \\
$65-74$ & $30.3(7.18)$ & $45.9(9.61)$ \\
$\geq 75$ & & $47.9(9.89)$ \\
Ethnicity & $33.7(8.17)$ & $44.7(10.34)$ \\
Afro & $30.7(7.78)$ & $45.1(10.21)$ \\
Indo & $33.6(10.62)$ & \\
Other & & $46.4(11.34)$ \\
Charlson Comorbidity Index & & $44.7(9.85)$ \\
$<3$ & $35.4(8.18)$ & $45.9(9.63)$ \\
$3-4$ & $30.8(8.27)$ & $44.7(10.70)$ \\
$5-6$ & $28.8(6.24)$ & \\
$7+$ & $26.4(3.53)$ &
\end{tabular}

Fig. 5 shows the Age $\times$ Ethnicity interaction plot of the mean PCS. As shown, for patients under 35 years of age, patients aged 35-44 years, and patients 55-64 years of age, the mean PCS of patients of Afro-Trinidadian descent was higher than that of those of Indo-Trinidadian descent and that the difference in mean PCS between these two ethnic groups was not significant for patients aged $45-54,65-74$, or 75 years or older.

Similar ANCOVA methods were used to test the equality of mean MCS, specifically for the PHQ depression categories $(p \leq 0.001)$ and the significant Age $\times$
Ethnicity interaction $(p=0.027)$. Adjusted means and corresponding standard deviations along with the number of patients are shown in the second column of Table 6; the Age $\times$ Ethnicity interaction plot is shown in Fig. 6.

The last column of Table 4 also shows that patients with no depression had higher mean MCS than those in every depression category and that mean MCS decreased with increasing level of depression; this was confirmed using regression methods.

Figure 6 shows the Age $\times$ Ethnicity interaction plot of the mean MCS. As shown, for patients under 35 years of age and patients aged 35-44 years, the mean MCS was higher among those of Indo-Trinidadian than among those of Afro-Trinidadian descent. There were no significant differences among the two groups for patients aged 45-54 and 55-74 years. However, for patients 6574 and patients 75 years or older, the mean MCS of patients of Afro-Trinidadian descent was significantly higher than that of their Indo-Trinidad counterparts.

\section{Predictors of quality of life}

Multivariable regression analysis was used to fit the following equation to the PCS and MCS data:

$$
\begin{aligned}
y= & \beta_{0}+\beta_{1} x_{1}+\beta_{2} x_{2}+\beta_{3} x_{3}+\beta_{4} x_{4}+\beta_{5} x_{5} \\
& +\varepsilon_{i}, \text { where } \\
x_{1}= & \text { Age, } x_{2}=\text { Sex }, x_{3}=\text { Ethnicity }, \\
x_{4}= & \text { Number of comorbidities, } \\
x_{5}= & \text { PHQ categories }
\end{aligned}
$$

The regression coefficients for each model are shown in Table 5 for PCS and MCS, respectively.

As seen in Table 5 , of the five independent variables only age $(p \leq 0.001)$, number of comorbidities $(p=$ $0.002)$, and PHQ category ( $p \leq 0.001)$ were predictors of the PCS. For the MCS, the predictors were age $(p=$

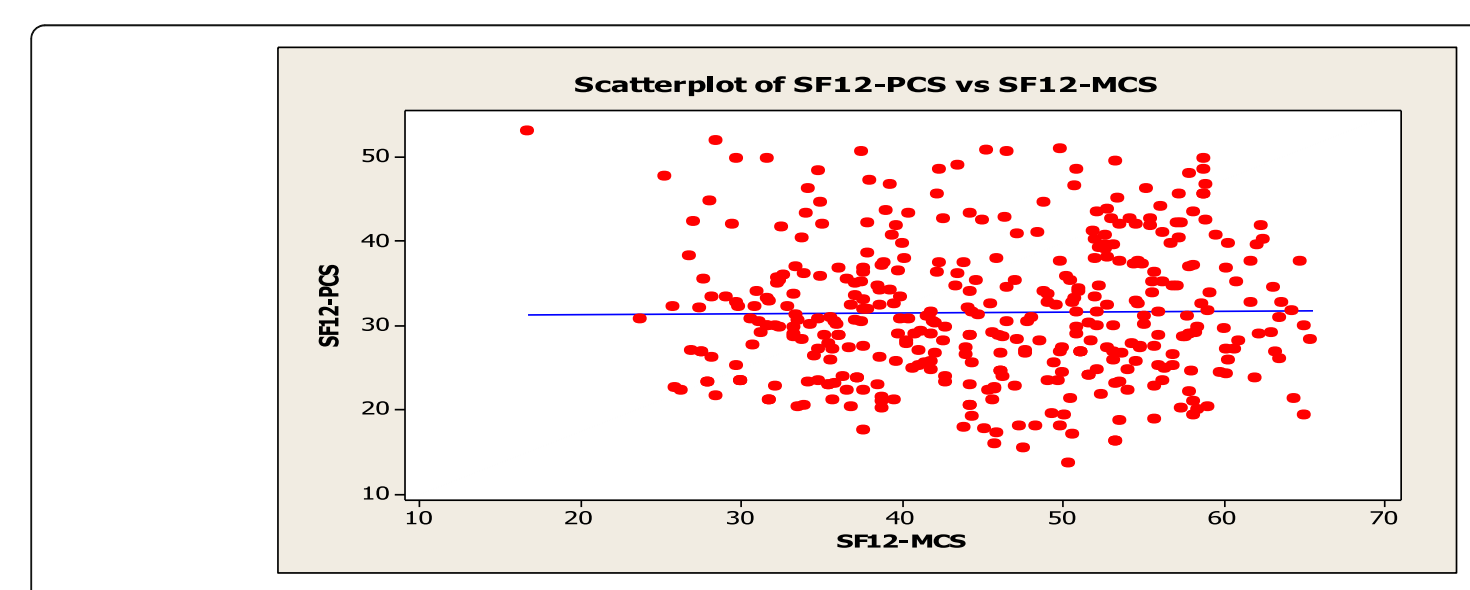

Fig. 4 Scatterplot of PCS vs. MCS 
Table 3 Self-reported and clinical depression (numbers and percents of patients)

\begin{tabular}{llll}
\hline $\begin{array}{llll}\text { Self-reported } \\
\text { depression: } n(\%)\end{array}$ & \multicolumn{2}{l}{ Clinical Depression: $\mathrm{n}(\%)$} & Total \\
\cline { 2 - 3 } & No & Yes & 61.6 \\
\hline No & $187(48.2)$ & $52(13.4)$ & 38.4 \\
Yes & $68(17.5)$ & $81(20.9)$ & \\
Total & 65.7 & 34.3 & \\
\hline
\end{tabular}

$0.033)$, sex $(p=0.002)$, and PHQ category $(p \leq 0.001)$. Coefficients of the two reduced models, with corresponding standard errors, are given in Table 6.

Therefore, the respective reduced prediction equations are:

$$
\hat{y}_{P C S}=46.67-0.116 x_{1}-1.709 x_{4}-2.134 x_{5},
$$

and

$$
\hat{y}_{M C S}=50.86-0.070 x_{1}-2.749 x_{2}-5.954 x_{5}
$$

\section{Discussion}

Overall, the mean PCS and MCS QOL scores in our study were 32.5 [95\% CI $(24.4,40.64)]$ and 45.4 [95\% CI $(44.4,46.4)]$, respectively. QOL scores worsened with increasing depression and were lower than those reported for a standardised US population. Lower QOL scores among patients with cardiac disease is a cause of national concern because of the high prevalence of depression among patients with cardiac disease in Trinidad [5]. Standard reference QOL values in Trinidad are not available. The relationship between comorbid depression and QOL is complicated, although, in general, the severity of depression is related to worsening QOL. Weiss et al. concluded that there was a strong association between depressive symptoms and reduced health related QOL [24]. Patients with depression after myocardial infarction had a higher probability of having a poor QOL [25]. This contradicts the findings of AbuRuz et al. [26] and may be related to the disease itself and its severity [12], the perception of the disease [27], or its consequences [28, 29] (social, psychological, and economic). Although physical health is affected by depression, the effect is less consistent and varies with the comorbid

Table 4 Adjusted PCS and MCS means by PHQ categories

\begin{tabular}{llll}
\hline \multirow{2}{*}{ PHQ Category } & & \multicolumn{2}{l}{ QOL Component: Mean (SD) } \\
\cline { 3 - 4 } None & & PCS & MCS \\
Mild & 84 & $36.3(8.11)$ & $53.7(6.50)$ \\
Moderate & 149 & $31.3(7.42)$ & $47.9(9.45)$ \\
Moderately Severe & 40 & $29.5(8.03)$ & $40.3(7.84)$ \\
Severe & 9 & $31.1(9.23)$ & $35.7(7.31)$ \\
\hline
\end{tabular}

medical condition [30]. Physical health deterioration in patients with cardiac disease with depression was reported by Ruo et al. [10]. Conversely, Allabadi et al. reported weak correlations between the Cardiac Depression Scale and SF-12-MCS and PCS scores [31].

Numerous studies have reported on QOL among patients with other comorbidities. Our study revealed that PCS QOL was generally worse with increasing number of comorbidities. Such findings were seen in several studies [32-34]. Patients with CVD with osteoarthritis comorbidity were found to have poorer physical health [35] and those with chronic obstructive pulmonary disease exhibited poorer physical fitness [36]. Shad et al. also reported that the MCS was significantly lower in patients with multiple comorbidities, with the MCS being related to sex and educational level [32]. Accompanying comorbidities are of concern, as our study reveals there was a considerable number of comorbidities, ranging from 0 to 4, among patients with cardiac disease.

Studies have shown an association between the presence of comorbidities in patients with heart failure (HF) and a lower QOL, leading to increased mortality risk [37]. Comorbid diabetes and depression were associated with decreased survival rates and increased rehospitalisation in patients with HF [38].

Studies have revealed that having a higher comorbidity burden had a higher association with more depressive symptoms and with poorer physical functioning, physical limitations, and poorer general health $[39,40]$.

\section{Interaction with age, ethnicity, and sex}

Our study revealed that there was a significant age and ethnicity interaction, with worsening QOL scores experienced with increasing depression. PCS QOL was higher among Afro-Trinidadian than among Indo-Trinidadian patients younger than 35, 35-44, and 55-64 years of age, but the difference was not significant among patients 75 years of age or older (Fig. 5). In contrast, with respect to MCS QOL, the reverse was generally true among IndoTrinidadians, where patients younger than 35 years of age and patients aged 35-44 years showed higher MCS than did Afro-Trinidadian patients, and the converse was true among patients 75 years of age or older (Fig. 6). The lower physical composite scores among young Indo-Trinidadians may have resulted from a sedentary lifestyle and possible over protection from relatives. Beata et al. reported that age had no effect on QOL [8]. However, AbuRuz et al. found age to be an independent predictor of poor QOL citing that anxiety and depression scores and disease severity increased with age, which would have led to a reduction in physical and mental abilities, resulting in the lower QOL [41] found among patients with HF. 


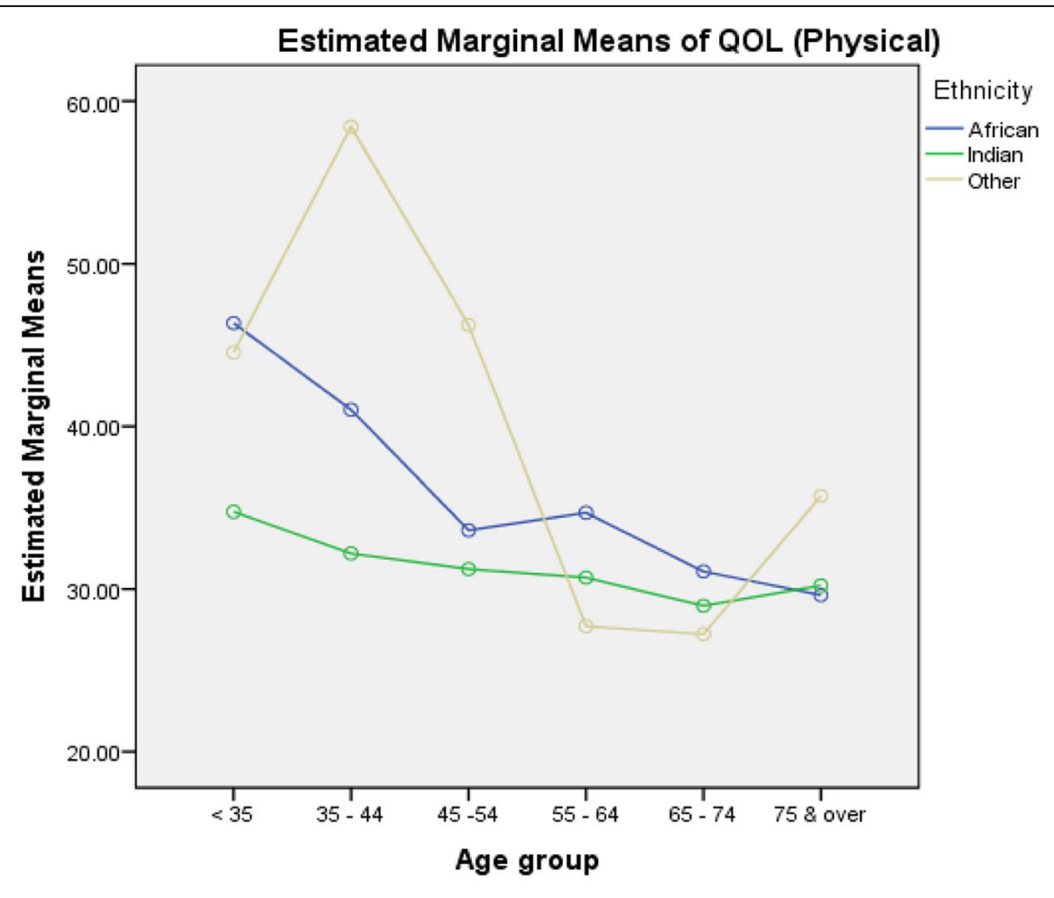

Covariates appearing in the model are evaluated the following values: Number of co-morbidities $=1.60$

Fig. 5 Age $\times$ Ethnicity interaction plot (PCS)

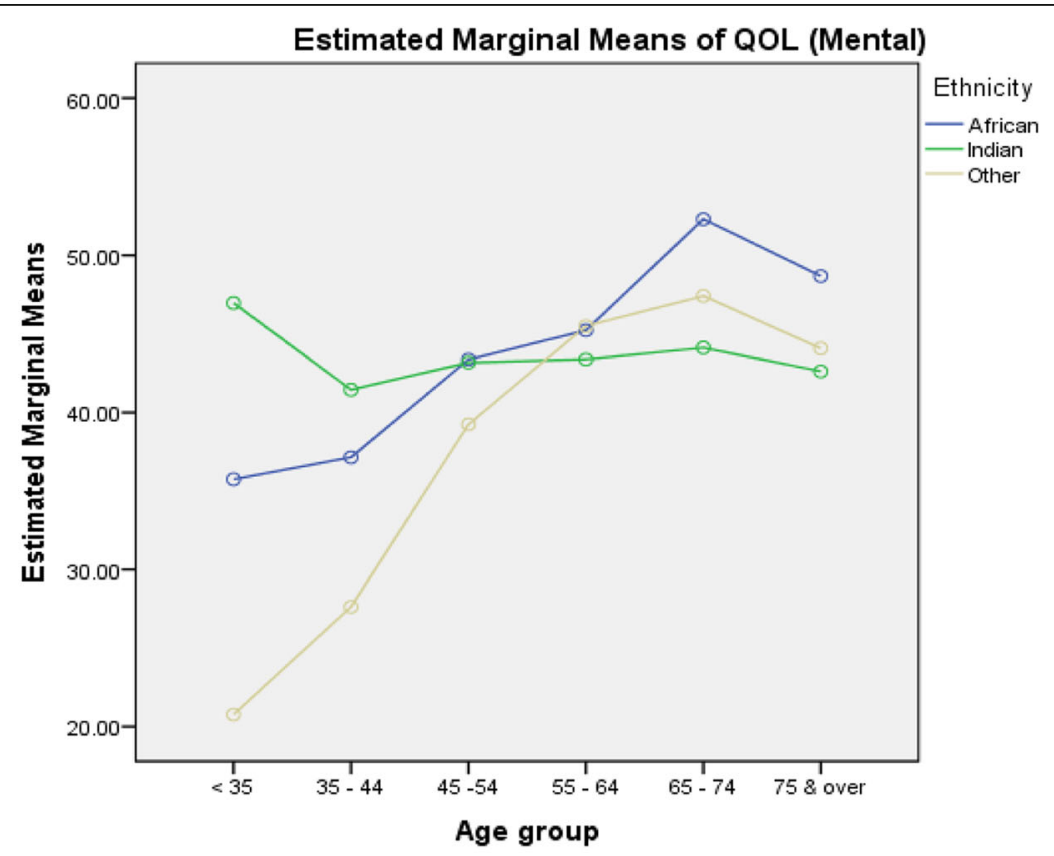

Covariates appearing in the model are evaluated at the following values: Number of co-morbidities $=1.60$

Fig. 6 Age $\times$ Ethnicity interaction plot (MCS) 
Table 5 Regression coefficients (dependent variables PCS and MCS)

\begin{tabular}{lllll}
\hline QOL Component & Variable & Coefficient $\left(\beta_{i}\right)$ & $\operatorname{se}\left(\hat{\beta}_{i}\right)$ & $p$-value \\
\hline PCS & Constant & 44.96 & 2.016 & $\leq 0.001$ \\
& Age & -0.114 & 0.030 & $\leq 0.001$ \\
& Sex & -0.659 & 0.783 & 0.401 \\
& Ethnicity & -0.340 & 0.559 & 0.543 \\
& Comorbidities & -1.643 & 0.527 & 0.002 \\
MCS & PHQ category & -2.09 & 0.390 & $\leq 0.001$ \\
& Constant & 51.73 & 2.193 & $\leq 0.001$ \\
& Age & 0.070 & 0.033 & 0.033 \\
& Sex & -2.624 & 0.852 & 0.002 \\
& Ethnicity & -0.782 & 0.608 & 0.199 \\
& Comorbidities & -0.548 & 0.574 & 0.340 \\
& PHQ category & -5.856 & 0.424 & $\leq 0.001$ \\
\hline
\end{tabular}

\section{Predictors and quality of life}

Our study revealed that age, depression, and number of comorbidities were predictors of PCS and that age, depression, and sex were predictors of MCS. The better QOL experienced by men may be related to our maledominant society or the greater exposure of men to support services in terms of social and physical activities. Najafi et al. also reported that male sex was an independent physical component predictor of higher QOL [42]. In contrast, Nesbitt et al. argued that male sex was associated with lower QOL [43] and that the sex difference was due to differences in family responsibility and gender roles and the responsibility of looking after one's own health. Dickens et al. reported that depression was a predictor of physical health-related QOL in patients with coronary heart disease (CHD) [44]. Similarly, another study observed significantly poorer health-related QOL among patients with CHD who had anxiety and depression in all domains, particularly, in physical functioning and role functioning [45]. AbuRuz reported that predictors of high depression levels among patients with

Table 6 Regression coefficients (dependent variables PCS and MCS)

\begin{tabular}{lllll}
\hline QOL Component & Variable & $\beta_{i}$ & $\operatorname{se}\left(\hat{\beta}_{i}\right)$ & $p$-value \\
\hline PCS & Constant & 46.67 & 2.067 & $\leq 0.001$ \\
& Age & -0.116 & 0.030 & $\leq 0.001$ \\
& Comorbidities & -1.709 & 0.521 & 0.001 \\
& PHQ category & -2.134 & 0.387 & $\leq 0.001$ \\
MCS & Constant & 50.86 & 2.110 & $\leq 0.001$ \\
& Age & 0.070 & 0.031 & 0.048 \\
& Sex & -2.749 & 0.843 & 0.001 \\
& PHQ category & -5.954 & 0.417 & $\leq 0.001$ \\
\hline
\end{tabular}

heart conditions were severity of disease, job status, and social support, which all led to poorer QOL [41]. Wang et al. reported that depression is a predictor of mental health-related QOL among patients with acute myocardial infarction [46]. Cruz et el found that depressed patients with IHD had lower QOL scores than did their non-depressed counterparts in the mental health, emotional, and social functioning domains [47]. Age and sex were predictors of MCS QOL. Hawkes et al. listed younger age as a predictor [48] and McBurney et al. found age below 65 years to be associated with low MCS- 12 scores [49]. El-baz et al. [50] and Duenas et al. [51] both found female sex to be a strong predictor of and have an association with lower mental health, respectively.

Depression among patients with cardiac disease must be identified especially when the principal concern is accompanied by comorbidities. This necessitates a simple depression screening tool, referral systems, and treatment strategies for patients.

\section{Limitations}

This was a single-centre study with a relatively small, convenience sample. Our results largely depended on self-reports and recall, which can be unreliable for many patients. Although patients were willing to share their feelings, many responses could have been exaggerated or under-reported. The sample was mainly of a lower socioeconomic background who seeks support from the free public health system. The stressors posed by personal economic conditions may also be exacerbating the prevalence of depression and as such, generalisation of the prevalence of depression in patients with CVD may prove difficult. Nonetheless, this study produced robust findings, highlighting the relationship between depression and QOL in patients with cardiac disease.

\section{Conclusions}

Psychosocial factors such as depression and comorbidities worsen physical and mental health QOL. There were significantly age and ethnicity interaction effects, with young Indo-Trinidadians being more greatly affected than young Afro-Trinidadians with regard to PCS, while the converse was found for MCS. As other studies [14] have shown depression worsens QOL, every effort must be made to identify patients with depression and patients who have comorbidities such as diabetes mellitus, hypertension, and hypercholesterolaemia.

\footnotetext{
Abbreviations

ANCOVA: Analysis of covariance; ANOVA: Analysis of variance; CAD: Coronary artery disease; CHD: Coronary heart disease; $\mathrm{Cl}$ : Confidence interval:

CVD: Cardiovascular disease; HF: Heart failure; IHD: Ischemic heart disease; MCS: Mental Component Scale; PCS: Physical Component Scale; PHQ: Patient Health Questionnaire; QOL: Quality of Life; SF12: 12-Item Short Form
} 


\section{Acknowledgements}

I wish to thank Kristian Sookram and Kelsey Rampersad, premedical students, who assisted with data collection and the participants, who gave their time to participate in the study.

\section{Authors' contributions}

MB conceptualised, designed, conducted, and reviewed the study and wrote and revised the manuscript. GL assisted in editing and performed the statistical analysis. KK assisted in statistical analysis. The authors read and approved the final manuscript.

\section{Funding}

Not applicable.

\section{Availability of data and materials}

The data that support the findings of this study are available from the corresponding author on request.

\section{Ethics approval and consent to participate}

Ethical approval was granted by the ethics committee of the South West Regional Authority on 21 October 2015. All participants provided their consent to participate in the study.

\section{Consent for publication}

Not applicable.

\section{Competing interests}

The authors declare that they have no competing interests.

Received: 17 October 2019 Accepted: 3 June 2020

Published online: 17 June 2020

\section{References}

1. Depression: definition [Internet]. Euro.who.int. 2019. https://www.euro.who. int/en/health-topics/noncommunicable-diseases/pages/news/news/2012/1 0/depression-in-europe/depression-definition Accessed 14 Aug 2019.

2. Hasin DS, Sarvet AL, Meyers JL, Saha TD, Ruan WJ, Stohl M, et al. Epidemiology of adult DSM-5 major depressive disorder and its specifiers in the United States. JAMA Psychiatry. 2018. https://doi.org/10.1001/ jamapsychiatry.2017.4602.

3. Minister of Health's statement on the observance of World Mental Health Day. Trinidad and Tobago Government News [Internet]. News.gov.tt. 2012. http://www.news.gov.tt/content/minister-healths-statement-observanceworld-mental-health-day\#.XVRCiONKiM - http://www.news.gov.tt/content/ minister-healths-statement-observance-world-mental-health-day\#. XSYqAutKiM8. Accessed 14 Aug 2019.

4. Celano CM, Huffman JC. Depression and cardiac disease: a review. Cardiol Rev. 2011. https://doi.org/10.1097/CRD.0b013e31820e8106.

5. Bahall M. Prevalence and associations of depression among patients with cardiac diseases in a public health institute in Trinidad and Tobago. BMC Psychiatry. 2019. https://doi.org/10.1186/s12888-018-1977-3.

6. Khawaja IS, Westermeyer JJ, Gajwani P, Feinstein RE. Depression and coronary artery disease: the association, mechanisms, and therapeutic implications. Psychiatry (Edgemont). 2009;6:38-51.

7. Haas DC. Depression and disability in coronary patients: time to focus on quality of life as an end point. Heart. 2006. https://doi.org/10.1136/hrt.2005. 066035.

8. Jankowska PB, Uchmanowicz I, Dudek K, Łoboz-Grudzień K. Impact of depression on quality of life results in patients following acute coronary syndrome treated with percutaneous coronary intervention (PCI). J Nurs Care. 2014. https://doi.org/10.4172/2167-1168.1000222.

9. Kessler RC, Bromet EJ. The epidemiology of depression across cultures. Ann Rev Public Health. 2013. https://doi.org/10.1146/annurev-publhealth-031912114409.

10. Ruo B, Rumsfeld JS, Hlatky MA, Liu H, Browner WS, Whooley MA. Depressive symptoms and health-related quality of life: the heart and soul study. JAMA. 2003. https://doi.org/10.1001/jama.290.2.215

11. The Impact of Depression on Daily Life. Depression Alliance. https://ec. europa.eu/health/ph_determinants/life_style/mental/docs/insidestory.pdf. Accessed 3 Aug 2019.
12. Juenger J, Schellberg D, Kraemer S, Haunstetter A, Zugck C, Herzog W, et al. Health related quality of life in patients with congestive heart failure: comparison with other chronic diseases and relation to functional variables. Heart. 2002. https://doi.org/10.1136/heart.87.3.235.

13. Van Jaarsveld CH, Sanderman R, Miedema I, Ranchor AV, Kempen GI. Changes in health-related quality of life in older patients with acute myocardial infarction or congestive heart failure: a prospective study. J Am Geriatr Soc. 2001. https://doi.org/10.1046/j.1532-5415.2001.49208.x.

14. Riedinger MS, Dracup KA, Brecht ML. Quality of life in women with heart failure, normative groups, and patients with other chronic conditions. Am J Crit Care. 2002;11:211-9.

15. Dixon T, Lim LL, Oldridge NB. The MacNew heart disease health-related quality of life instrument: reference data for users. Qual Life Res. 2002. https://doi.org/10.1023/a:1015005109731.

16. Huffman JC, Celano CM, Beach SR, Motiwala SR, Januzzi JL. Depression and cardiac disease: epidemiology, mechanisms, and diagnosis. Cardiovasc Psychiatry and Neurol. 2013. https://doi.org/10.1155/2013/695925.

17. May HT, Horne B, Knight S, Knowlton K, Bair T, Lappe D, et al. The association of depression at any time to the risk of death following coronary artery disease diagnosis: the intermountain inspire registry. J Am Coll Cardiol. 2017. https://doi.org/10.1093/ehjqcco/qcx017.

18. Utilisation Report of the Medical Records Department. South West Regional Health Authority, Ministry of Health, Trinidad. 2012.

19. Lwanga, S.K., Lemeshow, S. World Health Organization. Sample Size Determination in Health Studies: A Practical Manual 1991. https://apps.who. int/iris/handle/10665/40062.

20. Instruction Manual. Instructions for Patient Health Questionnaire (PHQ) and GAD-7 Measures. https://www.pcpcc.org/sites/default/files/resources/ instructions.pdf. Accessed 14 Aug 2019.

21. Charlson ME, Pompei $P$, Ales KL, MacKenzie CR. A new method of classifying prognostic comorbidity in longitudinal studies: development and validation. J Chronic Dis. 1987. https://doi.org/10.1016/0021-9681(87)90171-8.

22. Ware JE, Kosinski MA, Keller SD. SF-12: how to score the SF-12 physical and mental health summary scales. 1998. https://www.researchgate.net/ publication/242636950_SF-12_How_to_Score_the_SF-12_Physical_and_ Mental_Health_Summary_Scales. Accessed 14 Aug 2019.

23. How to score the SF-12 Health Survey Items. https://www.anesthesiologie. nl/uploads/files/PR 2 - Toelichting_SF-12v2.pdf. Accessed 14 Aug 2019.

24. Weiss M, Michels G, Eberhardt F, Fehske W, Winter S, Baer F, et al. Anxiety, depression and quality of life in acute high risk cardiac disease patients eligible for wearable cardioverter defibrillator: results from the prospective multicenter CRED-registry. PLoS One. 2019. https://doi.org/10.1371/journal.pone.0213261.

25. De Jonge P, Spijkerman TA, Van den Brink RH, Ormel J. Depression after myocardial infarction is a risk factor for declining health related quality of life and increased disability and cardiac complaints at 12 months. Heart. 2006. https://doi.org/10.1136/hrt.2004.059451.

26. AbuRuz ME, Alaloul F, Saifan A, Masa'deh R, Abusalem S. Quality of life for Saudi patients with heart failure: a cross-sectional correlational study. Glob J Health Sci. 2016. https://doi.org/10.5539/gjhs.v8n3p49.

27. Lau-Walker MO, Cowie MR, Roughton M. Coronary heart disease patients' perception of their symptoms and sense of control are associated with their quality of life three years following hospital discharge. J Clin Nurs. 2009. https://doi.org/10.1111/j.1365-2702.2008.02386.x.

28. Durmaz T, Ozdemir O, Ozdemir BA, Keles T, Bayram NA, Bozkurt E. Factors affecting quality of life in patients with coronary heart disease. Turk J Med Sci. 2009. https://doi.org/10.3906/sag-0901-26.

29. Shah SJ, Krumholz HM, Reid KJ, Rathore SS, Mandawat A, Spertus JA, et al. Financial stress and outcomes after acute myocardial infarction. PLoS One. 2012. https://doi.org/10.1371/journal.pone.0047420.

30. Thombs BD, Ziegelstein RC, Stewart DE, Abbey SE, Parakh K, Grace SL. Usefulness of persistent symptoms of depression to predict physical health status 12 months after an acute coronary syndrome. Am J Cardiol. 2008. https://doi.org/10.1016/j.amjcard.2007.07.043.

31. Allabadi A, Alkaiyat A, Alkhayyat A, Hammoudi H, Odeh J, Shtayeh M, et al. Depression and anxiety symptoms in cardiac patients: a cross-sectional hospital based study in a Palestinian population H. BMC Public Health. 2019. https://doi.org/10.1186/s12889-019-6561-3.

32. Shad B, Ashouri A, Hasandokht T, Rajati F, Salari A, Naghshbandi M, et al. Effect of multimorbidity on quality of life in adult with cardiovascular disease: a cross-sectional study. Health Qual Life Outcomes. 2017. https:// doi.org/10.1186/s12955-017-0820-8. 
33. Tušek-Bunc K, Petek D. Comorbidities and characteristics of coronary heart disease patients: their impact on health-related quality of life. Health Qual Life Outcomes. 2016. https://doi.org/10.1186/s12955-016-0560-1.

34. Sertoz OO, Aydemir O, Gulpek D, Elbi H, Ozenli Y, Yilmaz A, et al. The impact of physical and psychological comorbid conditions on the quality of life of patients with acute myocardial infarction: a multi-center, crosssectional observational study from Turkey. Int I Psychiatry Med. 2013. https://doi.org/10.2190/PM.45.2.a.

35. Prior JA, Jordan KP, Kadam UT. Associations between cardiovascular disease severity, osteoarthritis co-morbidity and physical health: a population-based study. Rheumatology. 2014. https://doi.org/10.1093/rheumatology/keu175.

36. Alosco ML, Spitznagel MB, Josephson R, Hughes J, Gunstad J. COPD is associated with cognitive dysfunction and poor physical fitness in heart failure. Heart Lung. 2015. https://doi.org/10.1016/j.hrtlng.2014.09.002.

37. Streng KW, Nautaa JF, Hillegea HL, Ankerb SD, Clelandc JG, Dickstein K. Non-cardiac comorbidities in heart failure with reduced, mid-range and preserved ejection fraction. Int J Cardiol. 2018. https://doi.org/10.1016/j. ijcard.2018.04.001.

38. Reeves GC, Alhurani AS, Frazier SK, Watkins JF, Lennie TA, Mose DK. The association of comorbid diabetes mellitus and symptoms of depression with all-cause mortality and cardiac rehospitalization in patients with heart failure. BMJ Open Diabetes Res Care. 2015. https://doi.org/10.1136/bmjdrc2014-000077.

39. Hoogwegt MT, Kupper N, Jordaens L, Pedersen SS, Theuns DAMJ. Comorbidity burden is associated with poor psychological well-being and physical health status in patients with an implantable cardioverterdefibrillator. EP Europace. 2013. https://doi.org/10.1093/europace/eut072.

40. Assari S, Lankarani MM, Ahmadi K. Comorbidity influences multiple aspects of well-being of patients with ischemic heart disease. Int Cardiovasc Res J. 2013;7:118-23.

41. AbuRuz ME. Anxiety and depression predicted quality of life among patients with heart failure. J Multidiscip Healthc. 2018. https://doi.org/10. 2147/JMDH.S170327.

42. Najafi M. Quality of life-associated factors among patients undergoing coronary artery bypass surgery as measured using the WHOQOL-BREF. Cardiovasc J Afr. 2009;20:284-9

43. Nesbitt T, Doctorvaladan S, Southard JA, Singh S, Fekete A, Marie K, et al. Correlates of quality of life in rural heart failure patients. Circ Heart Fail. 2014. https://doi.org/10.1161/CIRCHEARTFAILURE.113.000577.

44. Dickens C, Cherrington A, McGowan L. Depression and health-related quality of life in people with coronary heart disease: a systematic review. Eur J Cardiovasc Nurs. 2012. https://doi.org/10.1177/1474515111430928.

45. Rehman AU, Kazmi SF, Perveen S, Jabeen T. Health related quality of life among coronary heart disease patients, with and without anxiety \& depression. Pak Heart J. 2016. https://doi.org/10.6084/m9.figshare.4263296.v1.

46. Wang W, Chow A, Thompson DR, Koh K, Kowitlawakul Y, He HG. Predictors of health-related quality of life among patients with myocardial infarction. West J Nurs Res. 2016. https://doi.org/10.1177/0193945914546201.

47. Cruz LN, Fleck MP, Polanczyk CA. Depression as a determinant of quality of life in patients with chronic disease: data from Brazil. Soc Psychiatry Psychiatr Epidemiol. 2010. https://doi.org/10.1007/s00127-009-0141-2.

48. Hawkes AL, Patrao TA, Ware R, Atherton JJ, Taylor CB, Oldenburg BF. Predictors of physical and mental health-related quality of life outcomes among myocardial infarction patients. BMC Cardiovasc Disord. 2013. https:// doi.org/10.1186/1471-2261-13-69.

49. McBurney CR, Eagle KA, Kline-Rogers EM, Cooper JV, Mani OC, Smith DE, et al. Health-related quality of life in patients 7 months after a myocardial infarction: factors affecting the short Form-12. Pharmacotherapy. 2002 https://doi.org/10.1592/phco.22.17.1616.34121.

50. El-Baz N, Ondusova D, Studencan M, Rosenberger J, Reijneveld SA, van Dijk $J P$, et al. Differences between Slovak and Dutch patients scheduled for coronary artery bypass graft surgery regarding clinical and psychosocial predictors of physical and mental health-related quality of life. Eur J Cardiovasc Nurs. 2017. https://doi.org/10.1177/1474515117747571.

51. Dueñas M, Ramirez C, Arana R, Failde I. Gender differences and determinants of health related quality of life in coronary patients: a follow-up study. BMC Cardiovasc Disord. 2011. https://doi.org/10.1186/1471-2261-11-24.

\section{Publisher's Note}

Springer Nature remains neutral with regard to jurisdictional claims in published maps and institutional affiliations.

\section{Ready to submit your research? Choose BMC and benefit from:}

- fast, convenient online submission

- thorough peer review by experienced researchers in your field

- rapid publication on acceptance

- support for research data, including large and complex data types

- gold Open Access which fosters wider collaboration and increased citations

- maximum visibility for your research: over $100 \mathrm{M}$ website views per year

At BMC, research is always in progress.

Learn more biomedcentral.com/submissions 